\title{
The Potential of Electrifying China's Energy Use: an Analysis Based on STIRPAT Model
}

\author{
Yanmei Li*, Shuangshuang Lu \\ Department of Economics and Management, North China Electric Power University, Baoding 071000, China
}

Received: 9 April 2020

Accepted: 5 September 2020

\begin{abstract}
China's State Grid Corporation proposed the implementation of „electrifying energy use“ strategy in 2013, and strives to promote the use of electricity instead of coal and other fossil fuels in energy consumption, and ultimately achieve a fundamental change in energy development. We use the Stochastic Impacts by Regression on Population, Affluence and Technology (STIRPAT) model to quantify the potential of electrifying energy service in China. The extended STIRPAT model is applied to analyze the relationship between electricity demand and the influential factors (e.g. population, economic activity, electricity intensity, and energy structure). In order to effectively avoid multicollinearity among variables, the regression coefficients are calculated by using the Partial Least Squares (PLS) technique. Moreover, we use a hybrid model to project the Business as usual (BAU) development of the above explanatory variables. We then develop three scenarios to project and analyze the future potentials of electrification in China. From the projection results, the potential for electrification shows a trend that the growth rate is slow at first but accelerates later. The governmental policy support has the greatest impact on the potential for electrification, and the effect is most pronounced. The influence of technological level on the potential of electrification is gradually weakening. When China's economic growth slows down, the potential for growth in electrification will slow down, but the level of technology will slow the trend of slowing growth in electrification potential. Finally, the sensitivity and contribution of each factor are analyzed, based on which some suggestions to promote the development of electrification are put forward.
\end{abstract}

Keywords: electrification, STIRPAT Model, PLS, scenario analysis

\section{Introduction}

Energy consumption is one of the most important driving forces for economic development and social progress $[1,2]$. According to World Energy Outlook 2014, global energy demand will increase by $37 \%$

*e-mail: yanmei.li@ncepu.edu.cn during 2014-2040 [3]. China, as the world's second largest economy, facing growing energy shortage and increasing stress of air pollution and climate change [4-9]. In recent years, China's frequent occurrence of serious haze has mobilized the whole society's deep concern on environmental protection and profound reflection on China's energy development. The China Meteorological Administration's „Green Paper on Climate Change: Report on Climate Change" and a 
research report disclosed at the 2013 China Green Power Summit have shown that $50 \%$ to $60 \%$ of PM2.5 is originated from coal and $20 \%$ to $30 \%$ from oil. In addition, the statistics show that the energy intensity would reduce $3.7 \%$ if the proportion of electricity in final energy consumption increases $1 \%$. Based on this, the State Grid Corporation of China has formulated an implementation plan for electrification projects in its operating strategy in 2013. In the energy consumption market, the new energy consumption model is actively advocated as "replacing coal with electricity, replacing oil with electricity, and greening electricity generation", to increase the proportion of electricity in the final energy consumption. In order to achieve green development, China's" Thirteenth Five-Year Plan (20162020)“ has set very stringent constraints, including reducing energy consumption per unit of GDP by $15 \%$ within five years, reducing $\mathrm{CO}_{2}$ emissions per unit of GDP by $18 \%$, and total energy consumption by the end of the „Thirteenth Five-Year Plan” period will be controlled within five billion tons of coal equivalent (tce) $[10,11]$. Electrification is one of the effective ways to achieve these goals. Therefore, it is necessary to study the potential of electrifying China's energy use [12]. Only by clarifying the potential of China's electrification can we correctly assess the impact and significance of electrification implementation on China's energy conservation, greenhouse gas emission reduction, and environmental improvement. At the same time, the influencing factors affecting the potential of electrifying China's energy use should also be the focus of research. Only by clarifying the influencing factors of electrification potential [13], can we formulate corresponding electrification promotion strategies in a targeted manner [14].

The existing research on electrification in China mainly focuses on the comprehensive benefits of electrification, including economic benefits, environmental benefits and social benefits. Due to the high technical content of power equipment, the price is often higher than the price of traditional fossil energy equipment [15]; On the other hand, China's electricity price is also higher than coal and natural gas on per unit of energy basis, so the economic benefits of electrification are relatively low [16]. However, electricity is a secondary clean energy source, and no pollution is generated during use [17-20]. At the same time, the implementation of electrification can promote the development of grid modernization and intelligence and help alleviate the energy poverty. Therefore, the environmental benefits [21, 22] and social benefits [23-28] of electrification are relatively high.

Researches on China's electrification potential can be classified into two categories. One is to quantitatively study China's electrification potential, and the other is to conduct qualitative research on China's electrification potential. In the quantitative studies of electrification potential, it can be divided into two categories according to the different research methods. One is to use the consumption of fossil energy in the region or a certain proportion of fossil energy consumption as the potential for electrification, and then carry out simple calculations. Le et al [29] used fossil energy or a proportion of fossil energy consumed in the construction, industrial, transportation, agricultural and agricultural processing industries in Fujian Province as the potential for electrification in Fujian Province, and calculated accordingly. Zhi-Liang, Zhi-Liang $\mathrm{W}$ et al. [30] takes the difference between the proportion of China's Shandong Province's electric energy consumption in final energy consumption and the proportion of electric energy consumption in final energy consumption in the developed countries as the ratio of calculating electrification potential, and calculated the potential for electrification of Shandong Province according to this ratio. The other is to define and quantify the amount of electrification and use this as the potential for electrification, and then conduct related quantitative research accordingly. Sun Y., Zhou. $S$ et al. [31] defined the amount of electrification, and then selected the three factors of population, economic growth and technical level as the main influencing factors of electrification potential from the demand side, and used nonlinear regression combined with wavelet neural network to fit the influencing factors with the electrification potential, then set different development scenarios according to the influencing factors and calculated the corresponding electrification potential; Yi S et al. [32] defined the amount of electrification, and then selected three factors of technological development, economic factors and policy measures as the main influencing factors of electrification potential, and the particle swarm optimization support vector machine was used to fit the electrification potential and the influencing factors.

In summary, electrification has great environmental and social benefits, which is of great significance for reducing energy consumption and improving the environment. Therefore, it is necessary to study the potential of electrification.Qualitative researches on the potential of electrification can enhance the overall understanding of the electrification potential of a particular region, but it cannot obtain specific quantitative data of electrification potential. In the quantitative researches of electrification potential, the calculation of simple calculation based on the consumption of fossil energy in a certain proportion often neglects the limitations of some objective conditions, and the calculated data has low credibility. However, the existing researches consider fewer influencing factors and does not consider the multicollinearity between the influencing factors. To fill this gap, this article applies the extended STIRPAT model, selects the four effects of population, economic activity, electricity intensity, and energy structure from the demand side as the main factors affecting the electrification potential, and fully considers the multicollinearity between the influencing factors. 
The electrification potential and influencing factors are fitted by a PLS method that can effectively overcome the instability of the fitting equation due to multicollinearity. Next, we use a hybrid model to project the BAU development of the related influencing factors. We then develop three scenarios to project and analyze the future potentials of electrification in China. Finally, some suggestions for electrification work are put forward based on analyzing the prediction results.

This paper is organized as follows: Section 2 introduces the main methodologies and data source used in this paper; Section 3 solves model parameters and verifies the effectiveness of the model; Section 4 develops three scenarios and projects the potentials of electrification in China; Section 5 concludes the paperand then some suggestions for electrification work are put forward.

\section{Material and Methods}

\section{The Extended STIRPAT Model and Influencing Factors}

IPAT (Human impact of population, affluence and technology) model was first proposed in 1970s by American ecologist Ehrlich and Holden [33, 34]. The IPAT model and its derived models were widely used in the projection of carbon emissions, water resources efficiency, development assessment, etc. [35-38]. However, IPAT model and its related improvement models all have a common premise, the premise assume that each decomposition factor has the same effect. This premise limits the application of the IPAT model [39, 40]. To overcome the limitation, The Stochastic Impacts by Regression on Population, Affluence and Technology (STIRPAT) model was advanced by Dietz and Rosa which is written as $\mathrm{I}=\mathrm{aP}^{\mathrm{b}} \mathrm{A}^{\mathrm{c}} \mathrm{T}^{\mathrm{d}}$. The STIRPAT model and extended STIRPAT models were successfully used in $\mathrm{CO}_{2}$ emissions forecasting, which each influencing factor has different effect to the decomposed [41-43]. Another advantage of the STIRPAT model is its easiness to add explanatory variables.

According to the IPAT model, the influencing factors of electrification potential are grouped into three categories. The first is $\mathrm{P}$ which refers to Population.
The second is A which is typically represented by per capita gross domestic product (GDP). The third is T, represented by the technical level of electrification and government policy support. In recent years, the Chinese government has continuously adjusted its energy structure [44] to guide the development and utilization of clean energy. Therefore, the electricity intensity is used to represent the technical level of electrification and energy structure is used to represent the government's policy support [45]. The specific meaning of the influencing factors is shown in Table 1 below.

In practical application, the STIRPAT model is usually rewritten into a linear form by taking the logarithm. Accordingly, the extended STIRPAT model in this paper further rewritten as follows:

$$
\operatorname{In} E T_{t}=\operatorname{In} a+b \operatorname{In} P_{t}+c \operatorname{In} G_{t}+d \operatorname{In} E I_{t}+e \operatorname{In} E S_{t}
$$

...where the subscript $\mathrm{t}$ represents year $\mathrm{t}$; $E T$ is the amount of electricity that replaces other sources of energy; $P$ is the population; $G$ is GDP per capita; $E I$ is the electricity intensity; $E S$ is the proportion of electricity in all energy consumption.

\section{Multicollinearity Test}

Multicollinearity means that the estimated variables in a linear regression model are distorted or difficult to estimate due to the existence of a precise correlation or a highly correlated relationship.The factors influencing the electrification potential chosen in this paper, due to the common influence of social and economic environment, usually have similar change trends, so, multicollinearity is common in Eq.(1). At present, the commonly used multicollinearity diagnostic methods are independent variables correlation coefficient matrix $\mathrm{R}$ diagnostic method, the variance influence factor (VIF) diagnosis method, multiple decision coefficient value diagnosis method, correlation test, $\mathrm{F}$ test and so on. The first three methods have the problem that the threshold is not easy to determine. The method of correlation coefficient is only suitable for two vectors. In this paper, $F$ test is chosen as a method for detecting multicollinearity. The F statistic can test the multicollinearity effectively. The equation of $\mathrm{F}$ test is written as follows:

Table 1. The definitions for factors used in extended STIRPAT model.

\begin{tabular}{|c|c|c|c|}
\hline Factors & Notation & Definitions of Variables & Unit \\
\hline Electrical energy substitution & ET & The potential of electrifying China's energy use & TWh \\
\hline Population & P & The total number of people or residents in China & $10^{4}$ people \\
\hline Economic activity & G & GDP per capita & RMB \\
\hline Electricity intensity & EI & Electricity using required per unit of GDP & $\mathrm{kWh} / 100 \mathrm{RMB}$ \\
\hline Energy structure & ES & The proportion of electricity in all energy consumption & $\%$ \\
\hline
\end{tabular}




$$
\mathrm{F}=\frac{E S S /(P-1)}{R S S /(N-P)} \sim F(P-1, N-P)
$$

...where, ESS is the explained sum of squares; RSS is the residual sum of squares; $\mathrm{P}$ is the number of independent variables in Equation (1), and $\mathrm{N}$ is the number of samples.

\section{Partial Least Squares Model}

Linear form of the STIRPAT model is usually using the ordinary least squares (OLS) method to solve the parameters. However, if there is multicollinearity between variables, it will directly cause the instability of regression parameters and indirectly lead tomany inevitable consequences. In order to overcome the problem, Wold et al. [46] advanced the partial least squares (PLS) method. Many studies have shown that PLS algorithm can effectively avoid the multicollinearity between variables and has the ability to find the stable regression parameters [47]. Therefore, we use PLS algorithm to estimates the parameters of the extended STIRPAT model in this paper.

PLS algorithm combines multiple linear regression analysis, principal component analysis and Canonical correlation analysis, it has the advantages compared to ordinary least-squares regression. Therefore, it is called second-generation regression analysis method. The steps of the modeling method: Supposing the number of dependent variables and independent variables is $\mathrm{p}$ and $\mathrm{q}$, respectively, in order to study the statistical relationship between the dependent variables and the independent variables, there are $\mathrm{n}$ sample points were observed, thus forming the data tables $\mathrm{X}$ and $\mathrm{Y}$ of the independent variables and the dependent variables. Partial Least Squares Regression Extracts $t$ and $u$ in $\mathrm{X}$ and $\mathrm{Y}$, respectively, requires that: (1) $\mathrm{t}$ and $\mathrm{u}$ should carry the variation information in their respective data tables as much as possible; (2) the degree of correlation between $\mathrm{t}$ and $\mathrm{u}$ can be maximized. After the first component is extracted, the partial least squares regression is performed by the regression of $\mathrm{X}$ on $\mathrm{t}$ and the regression of $\mathrm{Y}$ on $\mathrm{t}$, respectively. If the regression equation has reached a satisfactory precision, the algorithm terminates, otherwise, the second round of component extraction will be performed using the residual information that after $\mathrm{X}$ and $\mathrm{Y}$ are interpreted by t. So back and forth until it achieves a more satisfactory accuracy. If a number of components are finally extracted from $\mathrm{X}$, the partial least squares regression will be performed by $\mathrm{yk}$ for the regression of these components of $\mathrm{X}$ and then expressed as $\mathrm{yk}$ regression equation for the original independent variable.

\section{Hybrid Projection Model}

In this paper, it is necessary to set different development scenarios to understand the influence of influencing factors in Eq. (1). on the potential of electrification, In order to set the parameters of each scenario more reasonably and effectively, it is necessary to understand the natural variation trends of each influencing factor. In recent years, the grey prediction model represented by GM $(1,1)$ has been widely used [48-50]. However, in practical applications, it has been found that the fitting or predicting effect of this model is sometimes good, sometimes with a large deviation, or even completely invalid. Two problems can be found by analyzing the modeling principle of the GM (1,1) model: (1) The grey prediction model can essentially be considered as an index prediction model, so, its prediction accuracy is related to the gradient law of the predicted object and the smoothness of the data sequence; (2) The discrete fitting equation established by the grey differential fitting method is an approximate difference equation, so, it is difficult to ensure that the fitting equation is strictly approximated to the differential equation of the system to be fitted. Therefore, in order to improve the applicability of GM $(1,1)$, this paper uses a hybrid projection model composed of GM $(1,1)$ and a linear model to predict the natural variation trend of influencing factors [51]. The projection equation of this model to the $\mathrm{k}+\mathrm{l}^{\text {th }}$ value of the time series is written as:

$$
\left\{\begin{array}{l}
\hat{\mathrm{x}}_{(\mathrm{k}+1)}=\hat{\lambda}_{1} \hat{\mathrm{x}}_{(\mathrm{k})}+\hat{\lambda}_{2} k+\hat{\lambda}_{3} \\
\hat{\mathrm{x}}_{(1)}=\mathrm{x}_{(1)}+\hat{\lambda}_{4}
\end{array}\right.
$$

...where $\hat{\lambda}_{1}, \hat{\lambda}_{2}, \hat{\lambda}_{3}$, and $\hat{\lambda}_{4}$ are the estimated parameters.

To estimate $\hat{\lambda}_{1}, \hat{\lambda}_{2}$, and $\hat{\lambda}_{3}$,

$$
\text { Let } \mathrm{Y}=\left[\begin{array}{c}
\mathrm{x}_{2} \\
\mathrm{x}_{3} \\
\ldots \\
\mathrm{x}_{\mathrm{n}}
\end{array}\right], \mathrm{B}=\left[\begin{array}{ccc}
\mathrm{x}_{(1)} & 1 & 1 \\
\mathrm{x}_{(2)} & 2 & 1 \\
\ldots & \ldots & \ldots \\
\mathrm{x}_{(\mathrm{n}-1)} & \mathrm{n}-1 & 1
\end{array}\right], \hat{\lambda}=\left[\begin{array}{c}
\hat{\lambda}_{1} \\
\hat{\lambda}_{2} \\
\hat{\lambda}_{3}
\end{array}\right]
$$

Then, the ordinary least squares estimator is

$$
\hat{\lambda}=\left(\mathrm{B}^{\prime} \mathrm{B}\right)^{-1} \mathrm{~B}^{\prime} \mathrm{Y}
$$

The estimation of $\hat{\lambda}_{4}$ is

$$
\hat{\lambda}_{4}=\frac{\sum_{\mathrm{k}=1}^{\mathrm{n}-1}\left[\mathrm{x}_{(\mathrm{k}+1)}-\hat{\lambda}_{1}^{\mathrm{k}} \mathrm{x}_{(1)}-\hat{\lambda}_{2} \sum_{\mathrm{j}=1}^{\mathrm{k}} \mathrm{j} \hat{\lambda}_{1}^{\mathrm{k}-\mathrm{j}}-\frac{1-\hat{\lambda}_{1}^{\mathrm{k}}}{1-\hat{\lambda}_{1}} \hat{\lambda}_{3}\right] \hat{\lambda}_{1}^{\mathrm{k}}}{1+\sum_{\mathrm{k}=1}^{\mathrm{n}-1}\left(\hat{\lambda}_{1}^{\mathrm{k}}\right)^{2}}
$$

Let $\mathrm{k}=1,2,3 \ldots$...in Eq. (3). The forecasting result for $\mathrm{x}_{(\mathrm{k})}$ is then obtained.

\section{Data Sources}

In order to achieve quantitative calculation of the potential of electric energy replacement, this paper 
defines the amount of electric energy substitution as an objective basis for analyzing the potential of electric energy replacement. Set the base year $T_{B}$. If the final energy consumption pattern maintains the base year level, the proportion of electricity in the final energy is the same as the base year. The energy consumption in the t-th year is defined as the energy replacement amount compared to the reference power consumption:

$$
D_{e, t}=\left(Y_{e, t}-\frac{Y_{e, T_{B}}}{Y_{T_{B}}} \cdot Y_{t}\right)
$$

...where: $D_{e, t}$ is the amount of electric energy replacement; $Y_{e, t}$ is the actual electric energy consumption of the first year; $Y_{t}$ is the total amount of final energy consumption in the $\mathrm{t}$-th year.

\section{Data Stationarity and Cointegration Test}

\section{Data Stationarity Test}

Before the prediction of the time series data, the stationarity test and the cointegration test are required. This paper uses ADF (Augmented Dickey-Fuller) unit root test method. We first set the significance level to $5 \%$, Hypothesis $\mathrm{H} 0$ : there is a unit root. If the test result is rejection of $\mathrm{H} 0$, there is no unit root and the sequence is stationary. Conversely, if the test result is acceptance of $\mathrm{H} 0$, there is a unit root, then the sequence is non-stationary. In the $\mathrm{ADF}$ test, the stationarity of the original sequence is first tested, and the ADF test equations have three cases in Intercept, Trend and intercept, and None. By comparing the AIC, SC, and HQ information criteria values in these three cases, the value of the Intercept case is the smallest. Explain that the sequence is a unit root process with an intercept term. The determined optimal lag order is 3 , and the lag interval is $[1,3]$. The unit root test was performed on

Table 2. Inspection result based on Augmented Dickey-Fuller.

\begin{tabular}{|c|c|c|c|}
\hline Variable & ADF t-Statistic & $5 \%$ level & Prob. $^{*}$ \\
\hline LNP & 0.800042 & -3.098896 & 0.9898 \\
\hline D(LNP) & -4.621841 & -3.098896 & 0.0034 \\
\hline LNG & -0.114487 & -3.875302 & 0.9857 \\
\hline D(LNG) & -7.274101 & -3.875302 & 0.0005 \\
\hline LNEI & -2.518538 & -3.791172 & 0.3156 \\
\hline D(LNEI) & -4.103298 & -3.875302 & 0.0360 \\
\hline LNES & -2.830788 & -3.933364 & 0.2189 \\
\hline D(LNES) & -8.400657 & -3.544284 & 0.0000 \\
\hline LNET & -2.660184 & -3.828975 & 0.2648 \\
\hline D(LNET) & -5.757649 & -4.107833 & 0.0078 \\
\hline
\end{tabular}

the original sequence, and the sequence was found to be non-stationary. Then, it is checked whether the sequence after the 1st difference is stationary. The sequence after the 1st difference is also the unit root process of the intercept, and the result is tested (see Table 2).

From this we can see that at the 5\% level of significance. LNP, LNG, LNEI, LNES and LNET accept the null hypothesis with a relatively high probability. In other words, the above five variables have unit roots. Let's take a look at their $1^{\text {st }}$ differential test. D (LNP), D (LNG), D (LNEI), D (LNES), D (LNET) all rejected the null hypothesis with a probability of less than 0.05 . That is, there is no unit root. Therefore, LNP, LNPG, LNEI, LNES, and LNET are all 1st differential stationary sequences. They are single-ordered and recorded as 1(1). Based on this, we guess that several variables are non-stationary sequences, but their linear combination may be stationary. We will conduct a cointegration test to explore whether there are co-integration relations between these non-stationary time series.

\section{Johansen Cointegration Test and Vector Error Correction Model}

Cointegration testing is the first step in cointegration analysis. Commonly used methods are the E-G two-step method and the Johansen cointegration test. The Johansen cointegration test is more comprehensive in the statistical test of time series economic variables. The basic idea is to transform a problem of finding the maximum likelihood function into a problem of finding the feature root and the corresponding feature vector based on the VAR model. This method extends the cointegration test to the case where there are multiple cointegration vectors. The original hypothesis of the Johansen cointegration test is that ,there is no cointegration relationship between variables". If both the trace statistic test and the maximum eigenvalue test reject the null hypothesis, it indicates that there is a cointegration relationship between the variables.

The VAR model is established and the optimal lag order of this model is determined to be 3 orders, so the VAR(3) model was built as follows.

\begin{tabular}{|c|c|c|c|c|c|c|c|c|c|}
\hline $\left.\ln (E T)_{t}\right]$ & \multirow{2}{*}{84.133} & \multicolumn{2}{|c|}{1.066} & \multicolumn{2}{|c|}{0.001} & -0.004 & $004-0.039$ & 0.008 & $\left\lceil\ln (E T)_{t-1}\right.$ \\
\hline $\ln (P)_{t}$ & & -20.0 & & 0.83 & & 3.73 & 1.817 & 0.831 & $\ln (P)_{t-1}$ \\
\hline $\ln (G)_{t}$ & -27.74 & 0.13 & & -0.0 & & 0.77 & -0.027 & 0.012 & $\ln (G)_{t-1}$ \\
\hline $\ln (E I)_{t}$ & -17.406 & 1.76 & & -0.0 & & -0.2 & 1.111 & 0.081 & $\ln (E I)_{t-1}$ \\
\hline $\ln (E S)_{t}$ & -19.95 & 1.37 & & 0.00 & & 0.18 & -0.609 & 0.093 & $\ln (E S)_{t-1}$ \\
\hline$[-0.177$ & -0.002 & -0.054 & 0.06 & 67 & -0. & $.036][$ & $\left\lceil\ln (E T)_{t-2}\right\rceil$ & & \\
\hline 17.578 & 0.186 & 0.495 & -1.6 & 675 & & 519 & $\ln (P)_{t-2}$ & & \\
\hline+-0.049 & 0.159 & -0.065 & -0.0 & .046 & & 003 & $\ln (G)_{t-2}$ & & \\
\hline-2.527 & 0.041 & 0.456 & -0.1 & 191 & & 023 & $\ln (E T)_{t-2}$ & & \\
\hline$[-0.301$ & 0.005 & 0.085 & 0.34 & 345 & & 132 & $\ln (E S)_{t-2}$ & & \\
\hline$[-0.041$ & -0.001 & 0.081 & -0.0 & 032 & 0.0 & 045 & $\ln (E T)_{t-3}$ & $\left.e_{1 t}\right]$ & \\
\hline-5.575 & -0.146 & -1.752 & 1.50 & 03 & & 501 & $\ln (P)_{t-3}$ & $e_{2 t}$ & \\
\hline 0.579 & -0.009 & -0.065 & -0.0 & 046 & -0.0 & .064 & $\ln (G)_{t-3}$ & $e_{3 t}$ & \\
\hline 1.952 & -0.041 & -0.518 & -0.0 & 049 & -0.1 & .146 & $\ln (E I)_{t-3}$ & $e_{4 t}$ & \\
\hline 0.603 & -0.005 & 1.404 & -0.5 & 592 & $-0 . C$ & .088 & $\ln (E S)_{t-3}$ & $e_{5 t}$ & \\
\hline
\end{tabular}


Table 3. Sequence cointegration test result.

\begin{tabular}{|c|c|c|c|}
\hline Hypothesized No.of CE(s) & Eigenvalue & Trace Statistic(P-values) & Max-Eigen Statistic(P-values) \\
\hline None ${ }^{*}$ & 0.715363 & $81.44608(0.0044)^{*}$ & $42.72241(0.0034)^{*}$ \\
\hline At most 1 & 0.501705 & $38.72367(0.2714)$ & $23.68313(0.1462)$ \\
\hline At most 2 & 0.226935 & $15.04054(0.7775)$ & $8.751335(0.8520)$ \\
\hline At most 3 & 0.168874 & $6.289206(0.6614)$ & $6.289115(0.5764)$ \\
\hline At most 4 & $2.67 \mathrm{E}-06$ & $9.06 \mathrm{E}-05(0.9937)$ & $9.06 \mathrm{E}-05(0.9937)$ \\
\hline
\end{tabular}

Max-eigenvalue test indicates 1 cointegrating eqn(s) at the 0.05 level

* denotes rejection of the hypothesis at the 0.05 level.

The goodness of fit for the five equation adjustments is: $R_{G}{ }^{2}=0.999 R_{E T}{ }^{2}=0.992 \quad R_{P}{ }^{2}=0.998 R_{E I}{ }^{2}=0.987$ $R_{E S}{ }^{2}=0.994$, So we can use this model for prediction and next analysis.

In this paper, the Johansen test method is used to perform the Johansen cointegration test. According to the principle of minimum AIC and SC, the optimal lag order is 3 . We performed the Johansen cointegration test on the variables LNP, LNG, LNEI, LNES and LNET through Eviews10 software and tested the results (see Table 3).

There is a cointegration relationship between LNET, LNP, LNPG, LNEI and LNES by Johansen cointegration test. We know that there is a cointegration relationship between LNET, LNP, LNPG, LNEI, and LNES, and there is a cointegration relationship between non-stationary variables. An error correction model can be established. We obtained five error correction models by performing error correction operations on Eviews10 software. The explanatory variable in the error correction model has 1 cointegration correction term, coinEq1. Explain the form of the 1st difference lag of the five endogenous variables in the first and second phases.

There is one cointegration equation by the Johansen cointegration test.

$E C_{1, t-1}=L N E T+108.0026 * L N P-4.200537 * L N G-2.440528 * L N E I$ $-34.83235^{*}$ LNES -1177.324

According to the VECM test, the regression results of VECM were obtained. The five regression results are as follows:

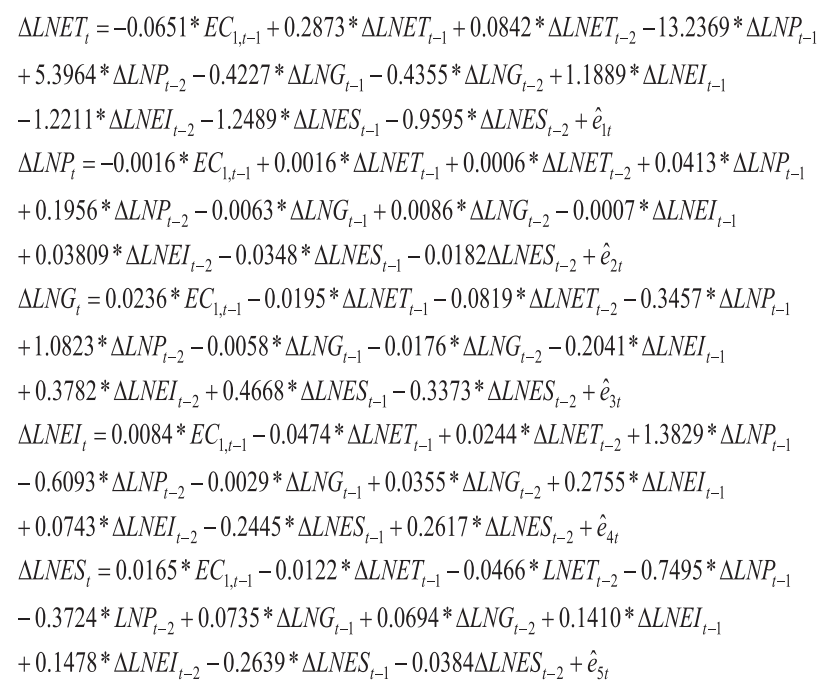

We obtained the long-term equilibrium relationship between LNET and LNP, LNPG, LNEI, and LNES through ECM correction. Therefore, we determined that there is a cointegration relationship between LNET, LNP, LNPG, LNEI and LNES, which can be used for time series prediction.

\section{Multicollinearity}

According to the calculation procedure of the $\mathrm{F}$ test, each influencing factor is used as a dependent variable one by one and other influencing factors are used as independent variables, and then a linear model is constructed by the OLS method. According to Equation (2), the F test values for each independent variable are shown in Table 4.

By querying the $\mathrm{F}$ distribution table, $\mathrm{F}(3,12)=3.490$, which is less than each value in table6,which indicates that there is multiple collinearity between the variables. In order to ensure the correctness of the results, we use the variance inflation factor (VIF) diagnostic method

Table 4. F test values for each independent variable.

\begin{tabular}{|c|c|c|c|c|}
\hline Dependent Variable & $\ln (\mathrm{P})$ & $\ln (\mathrm{G})$ & $\ln (\mathrm{EI})$ & $\ln (\mathrm{ES})$ \\
\hline $\mathrm{F}$ & 34.0137 & 371.5256 & 404.2593 & 90.5698 \\
\hline
\end{tabular}


Table 5. Multicollinearity statistics.

\begin{tabular}{|c|c|c|c|}
\hline Model & & Tolerance & VIF \\
\hline \multirow{3}{*}{1} & $\operatorname{Ln}(\mathrm{P})$ & 0.001 & 731.939 \\
\cline { 2 - 4 } & $\operatorname{Ln}(\mathrm{G})$ & 0.001 & 1130.437 \\
\cline { 2 - 4 } & $\operatorname{Ln}(\mathrm{EI})$ & 0.009 & 116.667 \\
\cline { 2 - 4 } & $\operatorname{Ln}(\mathrm{ES})$ & 0.056 & 18.000 \\
\hline
\end{tabular}

and tolerance method to test again whether there is multicollinearity between variables. The variables were subjected to collinearity diagnosis using SPSS software, and the collinear statistical results are shown in Table 5.

Generally, tolerance $<=0.1$ or VIF $>=10$ indicates that there is multicollinearity between variables. According to the test results in Table 5, which indicates that there is multicollinearity between variables, which is consistent with the results of the $\mathrm{F}$ test.

\section{PLS Model Parameter Solving}

In order to avoid the adverse consequences caused by the multicollinearity between the dependent variables, the PLS estimation technique is applied in this paper to calculate the regression coefficients of the extended STIRPAT model. Through operation the regression equation of the extended STIRPAT model can be obtained.

$$
\begin{aligned}
\operatorname{LnET}= & -64.1172+5.3481 \text { LnET }+0.2184 \text { LnET } \\
& -0.8611 \text { LnET }+0.7905 \text { LnET }
\end{aligned}
$$

Hybrid Forecasting Model Parameter Solving

According to the formula (3), (4), (5), the values of the hybrid projection model parameters are calculated, the obtained trend extrapolation equations for P,G,EI, and ES are

$$
\left\{\begin{array}{l}
P_{K+1}=0.72379 P_{K}+0.0014 K+3.2497 \\
P_{1}=P_{1}+1.0256 \times 10^{-5}
\end{array}\right.
$$

$$
\begin{gathered}
\left\{\begin{array}{l}
G_{K+1}=0.9704 G_{K}+0.0018 K+0.3948 \\
G_{1}=G_{1}-0.0274
\end{array}\right. \\
\left\{\begin{array}{l}
E I_{K+1}=0.73679 E I_{K}-0.01025 K+0.6891 \\
E I_{1}=E I_{1}-0.007042
\end{array}\right. \\
\left\{\begin{array}{l}
E S_{K+1}=0.60861 E S_{K} \\
E S_{1}=E S_{1}+0.16906
\end{array}\right.
\end{gathered}
$$

Model Validity

\section{PLS Model Validity}

In this paper, the projection results of electrification potential for each year were calculated according to Equation (7) and the actual data of each influencing factor from 1999 to 2014. To validate the model's performance, we will compare the projection results with the actual data and calculate the corresponding error, as shown in Table 6.

We used two common-use accuracy measures, including mean average percentage error (MAPE) and root mean square error (RMSE), to assess the model's validity. These error criterion indicators are expressed as Equations (12) and (13).

$$
\begin{array}{r}
\text { MAPE }=\frac{1}{N} \sum_{i=1}^{N}\left|\frac{\hat{y}_{i}-y_{i}}{y_{i}}\right| \times 100, \quad i=1,2, \ldots, N \\
\text { RMSE }=\sqrt{\frac{1}{N} \sum_{i=1}^{N}\left(\hat{y}_{i}-y_{i}\right)^{2}}, \mathrm{i}=1,2, \ldots, \mathrm{N}
\end{array}
$$

...where $y_{i}$ is actual data in the $i$ th year ( $i=1999,2000$, ..., 2014); $\hat{y}_{i}$ represents simulating result for the same period; and $\mathrm{N}$ is the number of data.

Though calculating, the MAPE and RMSE are 3.85\% and $4.95 \%$. In general, for annual data projections, the error range $[-5 \%,+5 \%]$ is considered reasonable and acceptable. According to the calculation results, the MAPE and RMSE values are within the error range.

Table 6. Projection results and errors (data in LN form, unit: $10^{4}$ tce).

\begin{tabular}{|c|c|c|c|c|c|c|c|c|}
\hline Year & 1999 & 2000 & 2001 & 2002 & 2003 & 2004 & 2005 & 2006 \\
\hline Actual Data & 0.10646 & 0.12477 & 0.15380 & 0.17439 & 0.20434 & 0.25431 & 0.36843 & 0.56520 \\
\hline Projection Results & 0.11745 & 0.11543 & 0.14265 & 0.17157 & 0.21554 & 0.2689 & 0.38796 & 0.55037 \\
\hline Error & $1.10 \%$ & $0.93 \%$ & $1.12 \%$ & $0.28 \%$ & $1.12 \%$ & $1.46 \%$ & $1.95 \%$ & $1.48 \%$ \\
\hline Year & 2007 & 2008 & 2009 & 2010 & 2011 & 2012 & 2013 & 2014 \\
\hline Actual Data & 0.63877 & 0.70664 & 0.82348 & 1.00107 & 1.15222 & 1.33322 & 1.54634 & 1.72423 \\
\hline Projection Results & 0.60408 & 0.72774 & 0.86098 & 1.00362 & 1.15434 & 1.32826 & 1.52936 & 1.73970 \\
\hline Error & $3.47 \%$ & $2.11 \%$ & $3.75 \%$ & $0.25 \%$ & $0.21 \%$ & $0.50 \%$ & $1.70 \%$ & $1.55 \%$ \\
\hline
\end{tabular}




\section{Hybrid Projection Model Validity}

Let $\mathrm{k}=1-15$ in Equations. (8)-(11), respectively, then, will receive the value of each influencing factor from 1999 to 2014. Fig. 1(a-d) show the fitting effects of the four influencing factors.

Fig. 1(a-b) show that the goodness of fit is high, the fitting curve almost coincides with the true value, the main reason is the changes of population and per capita GDP are stable. Fig. 1(c-d) show that the fitting curve conforms to the changing trend of the variable. Eg. in Fig. 1c). variable change is more dramatic before 2003, the change in the main trend of LnEI is smooth after 2003, since 2003 the fit between the variable and the predicted value curve is high.In Fig. 1d) although the change of LnES has been fluctuating from beginning to end, the overall increasing trend is consistent with the fitting curve. According to Fig. 2 of all the fitting errors are less than 0.15 , the results confirm the suitability of the hybrid projection model for extrapolating P, G, EI and ES.

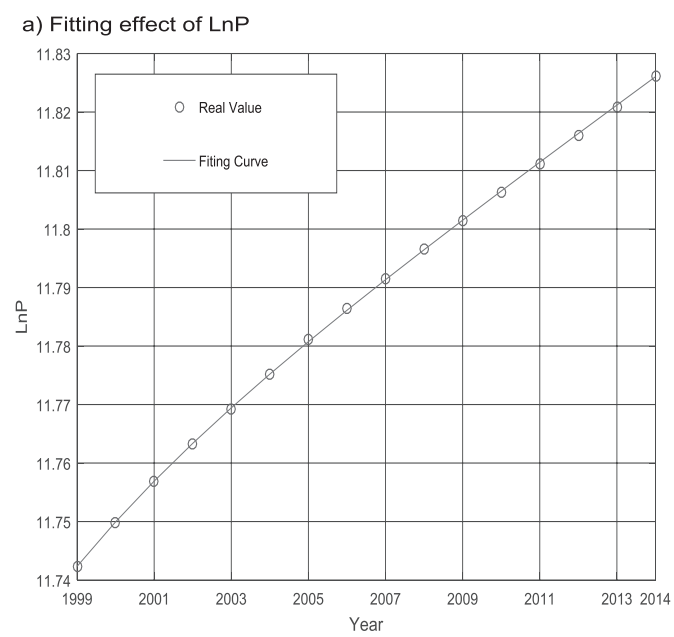

c) Fitting effect of $\mathrm{LnEI}$

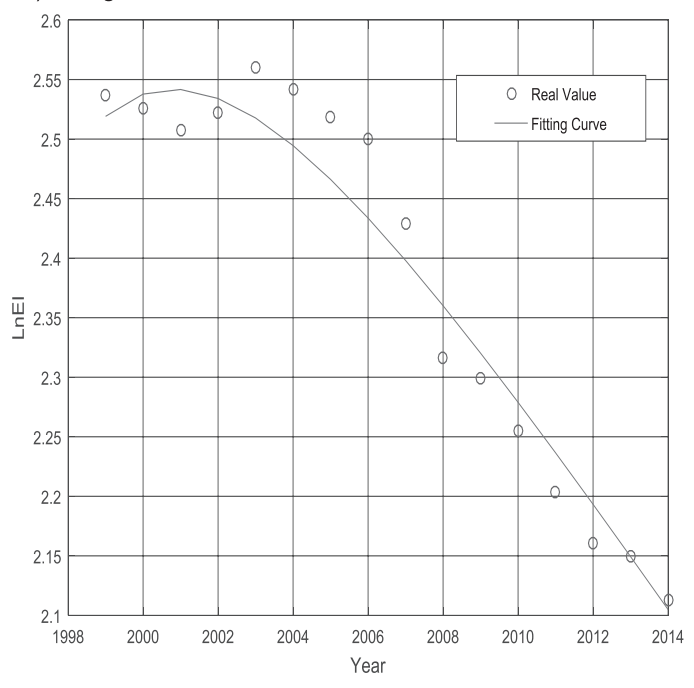

\section{Scenario Analysis}

\section{Scenarios Design}

The influencing factors of the electrification potential discussed in this paper are population $P$, GDP per capita $G(G=G D P / P)$, technical level EI $(\mathrm{EI}=\mathrm{E} / \mathrm{GDP}, \mathrm{E}$ is electricity consumption) and energy structure ES that represents governmental policy support.There are multiple collinearity among the four influencing factors. According to the graph of influence among various factors, as shown in Fig. 3, it shows that there are three fundamental factors affecting the four influencing factors, thus affecting the electrification potential, namely population, GDP, and electrification rate. Therefore, this paper will set different scenarios from the changes of these three factors, and analyze the electrification potential under each scenario.

The National Population Development Plan (20162030) pointed out that after the full implementation of the two-child policy, the birth population will increase during the "Thirteenth Five-Year Plan" period, and

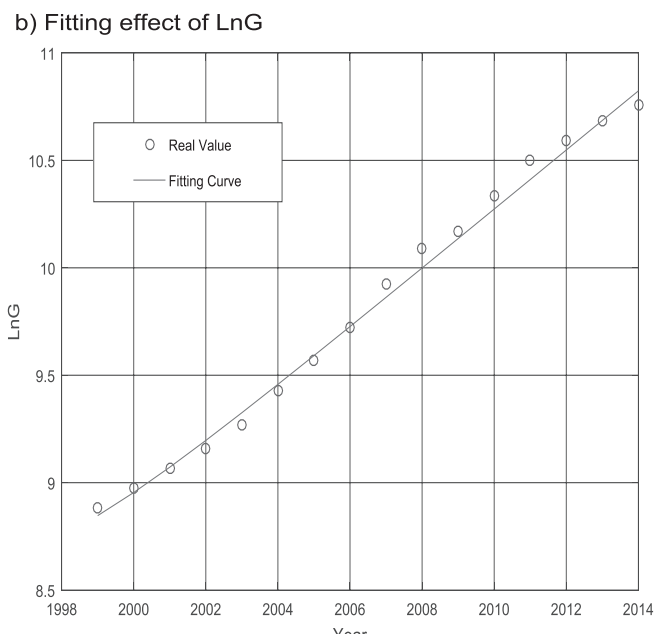

d) Fitting effect of LnES

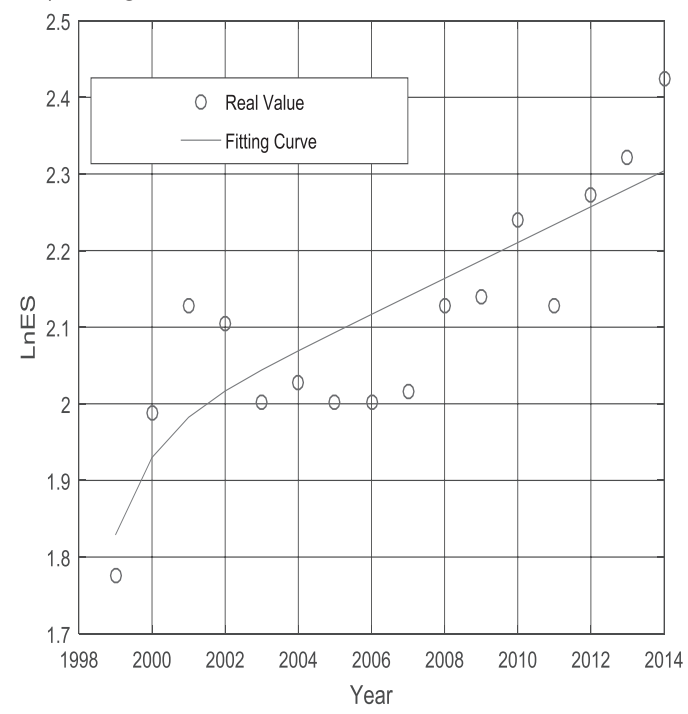

Fig. 1. Fitting effects of trend extrapolation equations. 


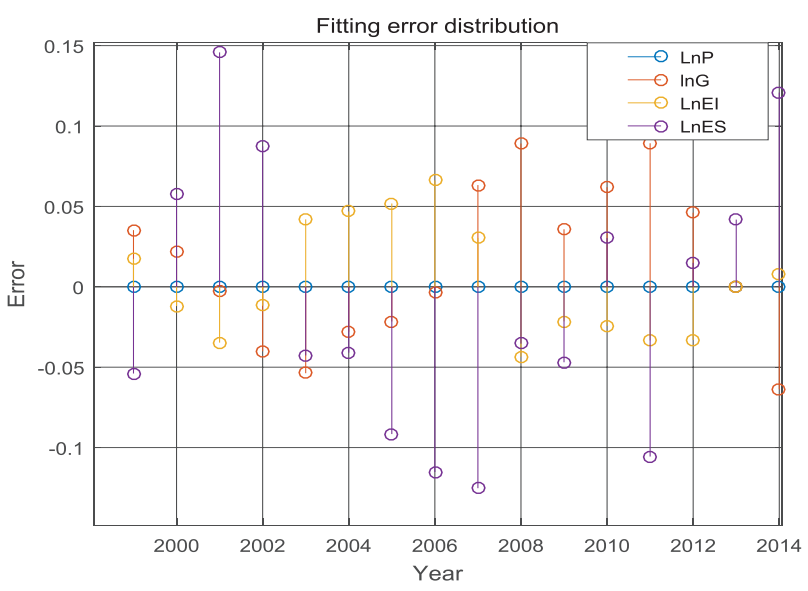

Fig. 2. Fitting errors distribution of trend extrapolation equations.

the rate of decline of the population's average annual growth rate will slow down. After the „Fourteenth FiveYear Plan", the number of women of childbearing age will decrease and the mortality rate caused by the aging of the population will increase. The population growth potential will weaken and the total population will reach a peak around 2030. According to the main objectives of the national population development plan, by 2020, the country's total population will reach 1.42 billion people, and by 2030 it will reach 1.45 billion people. According to the projection results of formula (8), as shown in Table 8 , by 2020, the population of China is 1.41 billion, and by the year 2030 the population is 1.48 billion. The projection results are basically consistent with the main goals of the national development plan. According to the historical data and projection data in Table 8, the average annual growth rate of the "Twelfth Five-Year Plan" period, the "Thirteenth Five-Year Plan" period, and the 2021-2030 period are 5\%o, 4.98\%o, and $2.35 \%$, respectively. The rate of decline gradually falls in line with the population growth [52].

From the above analysis, the projection results of the population forecasting model are consistent with the population growth in a period of time in the future, and are consistent with the country's main objectives for population development plan.Therefore, this paper will maintain the population trends in the past trends

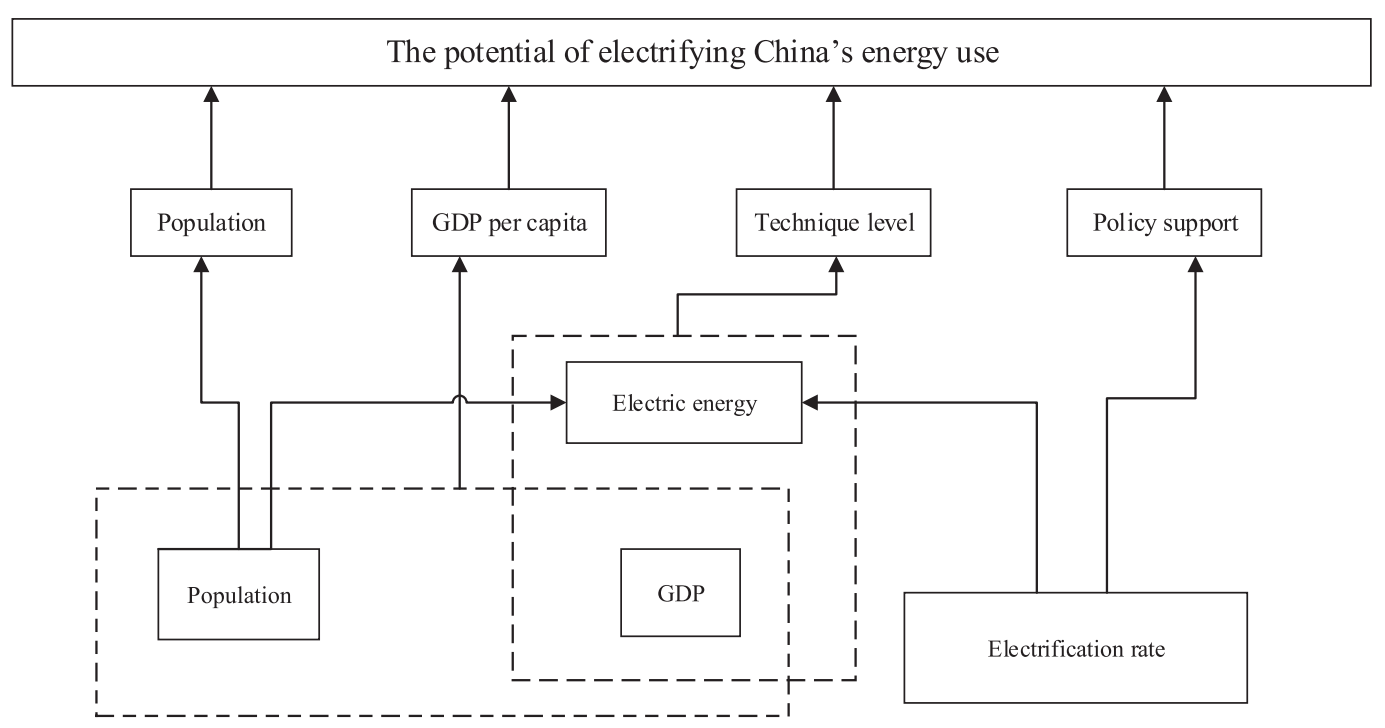

Fig. 3. The graph of influence among various factors. Note: $\rightarrow$ represent the direction of influence.

Table 7. Population data for 1999-2030.

\begin{tabular}{|c|c|c|c|c|c|c|c|c|c|c|}
\hline \multirow{4}{*}{ Historical Data } & Year & 1999 & 2000 & 2001 & 2002 & 2003 & 2004 & 2005 & 2006 & 2007 \\
\hline & $\mathrm{P}\left(10^{4}\right)$ & 125,786 & 126,743 & 127,627 & 128,453 & 129,227 & 129,988 & 130,756 & 131,448 & 132,129 \\
\hline & Year & 2008 & 2009 & 2010 & 2011 & 2012 & 2013 & 2014 & 2015 & 2016 \\
\hline & $\mathrm{P}\left(10^{4}\right)$ & 132,802 & 133,450 & 134,091 & 134,735 & 135,404 & 136,072 & 136,782 & 137,462 & 138,271 \\
\hline \multirow{4}{*}{ Projection Data } & Year & 2017 & 2018 & 2019 & 2020 & 2021 & 2022 & 2023 & & \\
\hline & $\mathrm{P}\left(10^{4}\right)$ & 138,905 & 139,598 & 140,294 & 140,993 & 141,695 & 142,401 & 143,110 & & \\
\hline & Year & 2024 & 2025 & 2026 & 2027 & 2028 & 2029 & 2030 & & \\
\hline & $\mathrm{P}\left(10^{4}\right)$ & 143,823 & 144,539 & 145,259 & 145,982 & 146,709 & 147,439 & 148,173 & & \\
\hline
\end{tabular}

Data Source: The projection data is calculated according to formula (8). 
as a common setting for each scenario.Three scenarios, BAU scenario, Medium and Low GDP growth scenario and Strong policy scenario, were set up based on the conversion of GDP and the government's adjustment of the energy structure.

Scenario 1: Business as usual (BAU) scenario

This scenario assumes that $\mathrm{P}, \mathrm{G}, \mathrm{EI}$ and ES in 2016-2030 will continue to follow their past development trends. That is, no significant population fluctuations, no major electric technological progress, no dramatic policy adjustments, and no fundamental socioeconomic changes occur during this period. This scenario is the baseline development result of the past trends. The trend extrapolation results of P, G, EI and ES from 2016-2030 can be obtained by the Hybrid model. By substituting the above trend extrapolation results into Eq.(7).

Scenario 2: Medium and Low GDP growth scenario

The 2016 government work report pointed out that during the "Twelfth Five-Year Plan" period, China's average annual growth rate of GDP was $7.8 \%$, and the total economic output ranked second in the world. Due to the problems of ecological environment and energy shortage, China's development mode during the „Thirteenth Five-Year Plan“ period has shifted from a high-speed growth stage to a high-quality development stage. The „Thirteenth Five-Year Plan for National Economic and Social Development" pointed out that the average annual economic growth rate during the „Thirteenth Five-Year Plan“ period remained at 6.5\%. In fact, according to statistics from the National Bureau of Statistics, the GDP growth rates in 2016 and 2017 were $6.7 \%$ and $6.9 \%$ respectively.Researchers have shown that before 2020, China's economic growth rate will not be lower than $6.5 \%$; in 2025 , it may fall back to about $5 \%$; in 2030 , it may be only $4 \%$, and then stabilize in $3 \% \sim 4 \%$ for a long time [53]. Therefore, in this scenario, the annual growth rates of 2018-2020, 2021-2025, and 2026-2030 GDP are $6.5 \%, 5 \%$, and 4\%, respectively. Based on the per capita GDP G $=$ GDP/P, the per capita GDP from 2016 to 2030 can be calculated, as shown in Table 9.As can be seen from the data in Table 5, under the medium and low GDP development model, the per capita GDP of $2018-2020$ is about $90 \%$ of the "natural" increase, and the per capita GDP of 2021-2025 is about $70 \%$ of the "natural" increase, the per capita GDP of 2026-2030 is about $60 \%$ of the" natural" increase. Therefore, the value of this scenario $G$ is set as shown in Table 11.

According to studies by $\mathrm{Hu}$ Zhaoguang and others, the correlation coefficient between electricity consumption and GDP in China is as high as 0.993 . That is, when the value of GDP changes, electricity consumption changes in the same direction.During the "Twelfth Five-Year Plan" period, the growth rate of China's electricity consumption slowed down overall. Due to the slowdown in economic growth and the adjustment of the industrial structure, the average annual growth rate was $5.7 \%$. However, in the long term, China's electricity demand still has a large room for growth. The growth rate will further slowdown.Judging from the process of industrialization in China, it is expected that by 2020 it will complete the process of industrialization and enter the stage of post-industrialization. It is expected that during the "Thirteenth Five-Year Plan" period, the average annual increase in electricity consumption will be $4.0 \%$. According to $\mathrm{Hu}$ Zhaoguang's scenario test results, under the low-speed GDP development model (the average GDP growth rate was $4.9 \%$ from 2020 to 2030), the growth rate of electricity consumption in the whole society was $2.5 \%$. Based on this growth rate, the GDP power consumption in 2016-2030 under the low-speed growth in the Chinese economy can be calculated from EI=E/GDP. The calculation results are shown in Table 10. From the data in Table 10, it can be seen that under the low-speed economic development model, the EI for 2016-2020, 2021-2025, and 20262030 are approximately $102 \%, 110 \%$, and $120 \%$ of "natural" growth respectively. Therefore, the value of the parameter EI is set as shown in Table 10.

The Thirteenth Five-Year Plan for Power Development (2016-2020) pointed out that by 2020, energy consumption in the energy end-use segment will replace bulk coal and fuel consumption by approximately 130 million tons of standard coal and increase the proportion of energy consumption in final energy consumption. Therefore, it is expected

Table 8. Projection results of per capita GDP indifferent development speeds.

\begin{tabular}{|c|c|c|c|c|c|c|c|c|}
\hline \multirow{4}{*}{$\begin{array}{c}\text { Natural growth projection } \\
\text { results }\end{array}$} & Year & 2017 & 2018 & 2019 & 2020 & 2021 & 2022 & 2023 \\
\cline { 2 - 8 } & $\mathrm{G}\left(10^{4} \mathrm{RMB}\right)$ & 5.901 & 6.543 & 7.246 & 8.014 & 8.853 & 9.769 & 10.767 \\
\cline { 2 - 9 } & Year & 2024 & 2025 & 2026 & 2027 & 2028 & 2029 & 2030 \\
\cline { 2 - 9 } & $\mathrm{G}\left(10^{4} \mathrm{RMB}\right)$ & 11.853 & 13.035 & 14.320 & 15.716 & 17.232 & 18.875 & 20.656 \\
\hline \multirow{3}{*}{$\begin{array}{c}\text { Projection results under } \\
\text { medium and low GDP growth }\end{array}$} & Year & 2017 & 2018 & 2019 & 2020 & 2021 & 2022 & 2023 \\
\cline { 2 - 9 } & $\mathrm{G}\left(10^{4} \mathrm{RMB}\right)$ & 5.955 & 6.310 & 6.687 & 7.086 & 7.404 & 7.735 & 8.082 \\
\cline { 2 - 9 } & Year & 2024 & 2025 & 2026 & 2027 & 2028 & 2029 & 2030 \\
\cline { 2 - 8 } & $\mathrm{G}\left(10^{4} \mathrm{RMB}\right)$ & 8.444 & 8.822 & 9.130 & 9.448 & 9.777 & 10.118 & 10.470 \\
\hline
\end{tabular}


Table 9. The projection results of EI.

\begin{tabular}{|c|c|c|c|c|c|c|}
\hline \multirow{4}{*}{$\begin{array}{c}\text { Natural growth projection } \\
\text { results }\end{array}$} & Year & 2016 & 2017 & 2018 & 2019 & 2020 \\
\cline { 2 - 7 } & EI(kWh/100RMB) & 7.877 & 7.579 & 7.291 & 7.014 & 6.747 \\
\cline { 2 - 7 } & Year & 2021 & 2022 & 2023 & 2024 & 2025 \\
\cline { 2 - 7 } & EI(kWh/100RMB) & 6.49 & 6.242 & 6.004 & 5.775 & 5.555 \\
\cline { 2 - 7 } & Year & 2026 & 2027 & 2028 & 2029 & 2030 \\
\cline { 2 - 7 } & EI(kWh/100RMB) & 5.343 & 5.139 & 4.943 & 4.754 & 4.572 \\
\hline \multirow{4}{*}{$\begin{array}{c}\text { Projection results under } \\
\text { medium and low GDP growth }\end{array}$} & Year & 2016 & 2017 & 2018 & 2019 & 2020 \\
\cline { 2 - 7 } & EI(kWh/100RMB) & 8.109 & 7.587 & 7.409 & 7.235 & 7.065 \\
\cline { 2 - 7 } & EI(kWh/100RMB) & 6.897 & 6.733 & 6.572 & 6.416 & 6.263 \\
\cline { 2 - 7 } & Year & 2021 & 2022 & 2023 & 2024 & 2025 \\
\cline { 2 - 7 } & Year & 6.173 & 6.084 & 5.996 & 5.91 & 5.824 \\
\hline
\end{tabular}

Table 10. Medium and Low GDP growth scenario parameters setting.

\begin{tabular}{|c|c|c|c|}
\hline Scenario 2 & \multicolumn{3}{|c|}{ Medium and Low GDP growth scenario } \\
\hline Variables & $2016-2020$ & $2021-2025$ & $2026-2030$ \\
\hline $\mathrm{P}$ & Natural growth & Natural growth & Natural growth \\
\hline $\mathrm{G}$ & $90 \%$ of natural growth & $70 \%$ of natural growth & $60 \%$ of natural growth \\
\hline EI & $102 \%$ of natural change & $110 \%$ of natural change & $120 \%$ of natural change \\
\hline ES & Natural growth & Natural growth & Natural growth \\
\hline
\end{tabular}

Scenario 3: Strong policy scenario

that the policy supports for electrification come from government will enter a peak period in the next few years. So, we assume that the strength of support in governmental policy support for electrification will increase in 2017-2030. According to the calculation of historical data, it can be concluded that the growth rates of the share of electricity in total energy consumption in the recent eight years of 2008-2016. According to the above analysis, we assume that the growth rate of electricity consumption in 2017-2030 is the average of the growth rate in the last eight years, i.e., the average annual growth rate is $5 \%$, and thenwe can calculate the value of ES in 2017-2030, as shown in Table 11 below. From the data in Table 11, it can be seen that

Table 11. The projection results of ES.

\begin{tabular}{|c|c|c|c|c|c|c|}
\hline \multirow{4}{*}{$\begin{array}{c}\text { Natural growth projection } \\
\text { results }\end{array}$} & Year & 2016 & 2017 & 2018 & 2019 & 2020 \\
\cline { 2 - 7 } & $\mathrm{ES}(\%)$ & 11.774 & 12.173 & 12.585 & 13.012 & 13.453 \\
\cline { 2 - 7 } & Year & 2021 & 2022 & 2023 & 2024 & 2025 \\
\cline { 2 - 7 } & $\mathrm{ES}(\%)$ & 13.908 & 14.380 & 14.867 & 15.371 & 15.891 \\
\cline { 2 - 7 } & Year & 2026 & 2027 & 2028 & 2029 & 2030 \\
\cline { 2 - 7 } & $\mathrm{ES}(\%)$ & 16.430 & 16.987 & 17.562 & 18.157 & 18.772 \\
\hline \multirow{4}{*}{$\begin{array}{c}\text { Projection results of annual } \\
\text { average growth rate of 5\% }\end{array}$} & Year & 2016 & 2017 & 2018 & 2019 & 2020 \\
\cline { 2 - 7 } & $\mathrm{ES}(\%)$ & 13.300 & 13.965 & 14.663 & 15.396 & 16.166 \\
\cline { 2 - 7 } & Year & 2021 & 2022 & 2023 & 2024 & 2025 \\
\cline { 2 - 7 } & $\mathrm{ES}(\%)$ & 16.975 & 17.823 & 18.714 & 19.650 & 20.632 \\
\cline { 2 - 7 } & Year & 2026 & 2027 & 2028 & 2029 & 2030 \\
\cline { 2 - 7 } & $\mathrm{ES}(\%)$ & 21.664 & 22.747 & 23.885 & 25.079 & 26.333 \\
\hline
\end{tabular}


Table 12. Strong policy scenario parameters setting.

\begin{tabular}{|c|c|c|c|c|}
\hline SF & P & G & EI & ES \\
\hline Scenario 3 & Natural growth & Natural growth & $120 \%$ of natural change & $120 \%$ of natural growth \\
\hline
\end{tabular}

the projection values of ES at an annual growth rate of $5 \%$ are about $120 \%$ of the „natural“ growth of ES. Therefore, the scenario sets the value of ES to $120 \%$ of „natural“" growth.

As the change of energy structure will lead to an increase in the use of electricity,so under the premise that P and GDP keep growing naturally, the value of EI will increase with the increase of social electricity consumption. This is mainly due to the fact that as the proportion of electricity consumption increases, the electricity used by the secondary industry also increases. However, the value-added electricity consumption of the secondary industry is usually six times that of the added value of the primary industry and the tertiary industry. It will cause the increase of GDP power, that is, the increase of EI. In the above section, the value of EI is set to $120 \%$ of the "natural" growth, that is, the use of electricity is 1.2 times that of the "natural" growth. From EI = E/GDP, if the GDP maintains ,natural“" growth, E changes by $120 \%$, then EI it will also change by $120 \%$, that is, the value of EI is $120 \%$ of „natural“ growth. Therefore, the values of each parameter in this scenario are set as shown in Table 12.

\section{Results and Discussion}

According to the parameters ${ }^{6}$ setting in different scenarios, the potential of electrifying China's energy use under different scenarios can be obtained according to Equation (7), shown in Table 13. As electrification is a process of continuous accumulation, the history of technology and policies implementation will still have an impact on the future, according to the formula (6) of the potential of electrifying energy service. The data in Table 14 refers to the increase in electrical energy consumption of the $\mathrm{t}$-th year compared to the baseline electrical power consumption.

In order to verify the rationality of the projection results, the electrification potential of each year of 2017-2030 can be calculated according to the data in Table 13. The results are shown in Table 14. According to research by $\mathrm{Hu}$ Zhaoguang et al., in 2030, electricity consumption is 9,808 TWh, which is bigger than the amount of electrification under three scenarios, and the primary energy demand and is 5.865 billion tce, in Scenario 3, when the electric energy ratio is $26.3 \%$, the power demand is $12,560 \mathrm{TWh}$, which is greater than 1,564 TWh. According to the "Thirteenth Five-Year

Table13. The potential of electrifying China's energy use under different scenarios.

\begin{tabular}{|c|c|c|c|}
\hline \multirow{2}{*}{ Year(t) } & \multicolumn{2}{|c|}{ ET unit: TWh } \\
\cline { 2 - 4 } & $\begin{array}{c}\text { Business as usual (BAU) } \\
\text { scenario }\end{array}$ & $\begin{array}{c}\text { Medium and Low GDP growth } \\
\text { scenario }\end{array}$ & Strong policy scenario \\
\hline 2016 & 2,939 & 2,751 & 4,145 \\
\hline $2016-2017$ & 3,605 & 3,610 & 5,022 \\
\hline $2016-2018$ & 4,346 & 4,194 & 5,989 \\
\hline $2016-2019$ & 5,097 & 4,785 & 6,982 \\
\hline $2016-2020$ & 5,870 & 5,394 & 9,015 \\
\hline $2016-2021$ & 6,661 & 5,994 & 10,196 \\
\hline $2016-2022$ & 7,475 & 6,607 & 11,350 \\
\hline $2016-2023$ & 8,309 & 7,234 & 12,551 \\
\hline $2016-2024$ & 9,169 & 7,872 & 13,802 \\
\hline $2016-2025$ & 10,054 & 8,524 & 15,108 \\
\hline $2016-2026$ & 10,970 & 9,122 & 16,471 \\
\hline $2016-2027$ & 11,918 & 9,735 & 17,897 \\
\hline $2016-2028$ & 12,899 & 10,364 & 19,389 \\
\hline $2016-2029$ & 13,917 & 11,010 & 20,953 \\
\hline $2016-2030$ & 14,976 & 11,673 & \\
\hline
\end{tabular}


Table 14. Incremental electrification potential value per year for 2017-2030.

\begin{tabular}{|c|c|c|c|}
\hline Year Units: TWh & Business as usual (BAU) scenario & Medium and Low GDP growth scenario & Strong policy scenario \\
\hline 2017 & 666 & 583 & 876 \\
\hline 2018 & 741 & 583 & 967 \\
\hline 2019 & 751 & 591 & 993 \\
\hline 2020 & 773 & 601 & 1,033 \\
\hline 2021 & 791 & 601 & 1,071 \\
\hline 2022 & 813 & 613 & 1,111 \\
\hline 2023 & 835 & 639 & 1,154 \\
\hline 2024 & 860 & 639 & 1,201 \\
\hline 2025 & 885 & 652 & 1,251 \\
\hline 2026 & 916 & 613 & 1,306 \\
\hline 2027 & 948 & 613 & 1,363 \\
\hline 2028 & 981 & 629 & 1,426 \\
\hline 2029 & 1,019 & 664 & 1,492 \\
\hline 2030 & 1,059 & 664 & 1,564 \\
\hline
\end{tabular}

Plan for Electric Power Development (2016-2020)", the potential for electrification is approximately $1,050 \mathrm{TWh}$ in 2020,which is similar to the electrified amount of $1,033 \mathrm{TWh}$ in the year 2020 under scenario 3. Based on the above analysis, the scenario projection results of this paper have certain rationality.

To clearly demonstrate the projection results. Fig. 4 presents all the develop trends of the scenarios by using the data in Table 9. Table 13 shows that the scenario with the greatest potential for electrification in 20162030 is the strong policy scenario (Scenario 3). In this scenario, by 2030 , the potential of electrification will reach 20,953 TWh. The scenario with the lowest potential for electrification is the medium and low GDP growth scenario (Scenario 2), and the potential of electrification under this scenario is $11,673 \mathrm{TWh}$ by 2030 , which is $22.05 \%$ lower than the $14,976 \mathrm{TWh}$ under the BAU scenario. Fig. 4. shows that the potential of electrification will visibly increase year by year before 2030 of all scenarios, and there will be no peak in this period. From the changes trend in the figure, it can be seen that the growth trend of the potential of electrification can be divided into two stages. Before 2025 is the first stage, the rate of increase of the potential of electrification is relatively slow, mainly because this stage is the primary stage of electrification, the electrification works just began to start one after another.The main electrification works are concentrated in the field of technology is relatively mature, such as, electricity replaces the scattered coal, coal-fired boilers, electric heating alternative coal-fired heating. For the energy-consuming industries, especially in the industrial sector, the electrification works has not been carried out in depth. People's environmental awareness is still in the transition stage, while the governmental policy supports for electrification are still in the experimental stage, not yet the formation of a stable and effective mechanism to promote the work of electrification. 2025-2030 is the second stage, in this stage the potential of electrification will begin to accelerate. The main reason is that after a period of exploration, an effective mechanism to promote electrification began to form. The governmental policy support efforts began to increase, and related policies are beginning to play a role in improving the economics of electrification, guiding energy users to select lowcarbon, high-efficiency energy. expanding the field of electrification and expanding the application range of electrification technology. At the same time, energy users $^{6}$ enthusiasm for electrification has also begun to increase.

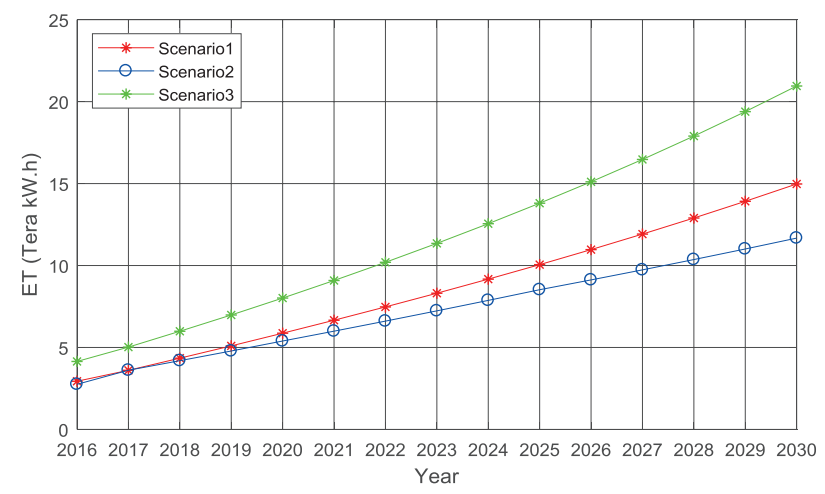

Fig. 4. The potential of electrifying China's energy use under different scenarios. 
In order to further analyze the projection results, taking the results of BAU scenario (scenario 1) as the baseline, the relative change rate of the potential of electrification for the other scenarios can be calculated according to Equation (14). To display the results more clearly and analyze reasonably, the values of relative change rate from 2016 to 2030 for the designed scenarios are plotted in histogram, shown in Fig 5. From the percentage change and the data in table10 several facts are concluded as follows:

$$
\mathrm{R}=\frac{E T_{i t}-E T_{S 1 \mathrm{t}}}{E T_{S 1 t}}
$$

...where $E T_{i t}$ represents the potential of Electrification for $t^{\text {th }}$ period $(t=2016-2030)$ in $i^{\text {th }}$ scenario $(i=2,3)$, and is the potential of Electrification for $t^{\text {th }}$ period $(t=2016-2030)$ in Scenario 1.

(1) It can be seen from Fig. 5 that as the downward pressure on the economy continues to increase, the percentage change of medium and low GDP growth scenario compared to BAU scenario also increases, which indicates that the growth speed of the electrification potential under medium and low GDP growth scenario is slower than the growth speed under the BAU scenario, but due to the technical level, the slowing down speed is not proportional to the deceleration of GDP growth. Strong technology support scenario compared to the BAU scenario, the percentage increase is relatively little, and the growth trend is the same as the BAU scenario. However, the increase in electrification potential is almost the same as the rate of change in governmental support. This change percentages indicate that the greater the government's support, the greater the potential for electrification, the faster the GDP growth, and the greater the potential for electrification. Governmental policy support will become the most important influencing factor in measuring the potential of electrification.

(2) Compared with the BAU scenario, the medium and low GDP growth scenario not only slows down the growth rate of GDP, but also slows down the progress of the technological level. From the data in Table 6,

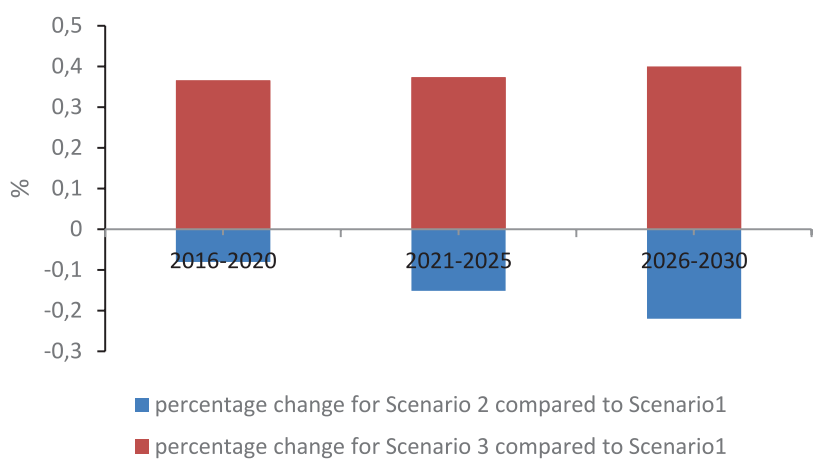

Fig. 5. Percentage change for designed scenarios in year 2016 and $2030(\%)$. it can be found that the EI which represents technical level gradually decreases, that is, the influence of technology level on the potential of electrification is gradually weakened. It can be seen from Fig. 5 that even if the technical level has less and less influence on the potential of electrification, However, with the gradual slowdown of GDP growth, the level of technology has slowed the trend of electrification potential growth speed slow down. In scenario 2, even though per capita GDP is $60 \%$ of the natural growth, however, by 2030 , the potential for electrification is $40 \%$ of the natural growth result. This shows that even if the economy goes down, China's economic aggregation is huge, and the potential of electrification is still great.

(3) In the strong policy scenario, the government increases its policy support for the use of electricity, and the use of electricity will gradually increase. According to the National Bureau of Statistics "China Energy Statistical Yearbook 2015", the electricity consumption in the secondary industry accounted for $73.6 \%$ of the total electricity consumption in 2014, which means that as the share of electricity used increases, the electricity consumed by the secondary industry will also gradually increase, the value-added electricity consumption of the secondary industry is usually about six times that of the primary and tertiary industries, which will cause the increase of GDP electricity consumption, so, the level of technology represented by EI appears reduction in scenario 3. However, from the specific numerical point of view, with the adjustment of the national policy on the share of electricity use, the technological level is promoting the increase in the potential for electrification.

\section{Conclusions}

As can be seen from the annual contribution of each variable tochanges of China's electrification potential in Fig. 6, the order of contribution from largest to smallest in 1999-2014 is LnP, LnG, LnES and LnEI. Among them, the contribution of both population and GDP per capita to electrification potential is as high as $86 \%$. According to Eq. (7) the partial P,G,EI and ES elasticity of ET are 5.348,0.2184,-0.8611 and 0.7905 respectively. As can be seen, the key factors that affect the potential of electrification lie in population, governmental policy support, GDP per capita.Technical level will slow down the growth of electrification potential.

The contribution made by the population to electrification potential in 1999-2014 has been consistently relatively stable with an average change of no more than $2.6 \%$. This is mainly due to the steady change in population in China over the past few decades. In recent years, the population aging in China has accelerated, the growth rate will start to slow down and the population changes will begin to fluctuate. This undoubtedly will have an impact on the development of electrification in China. 


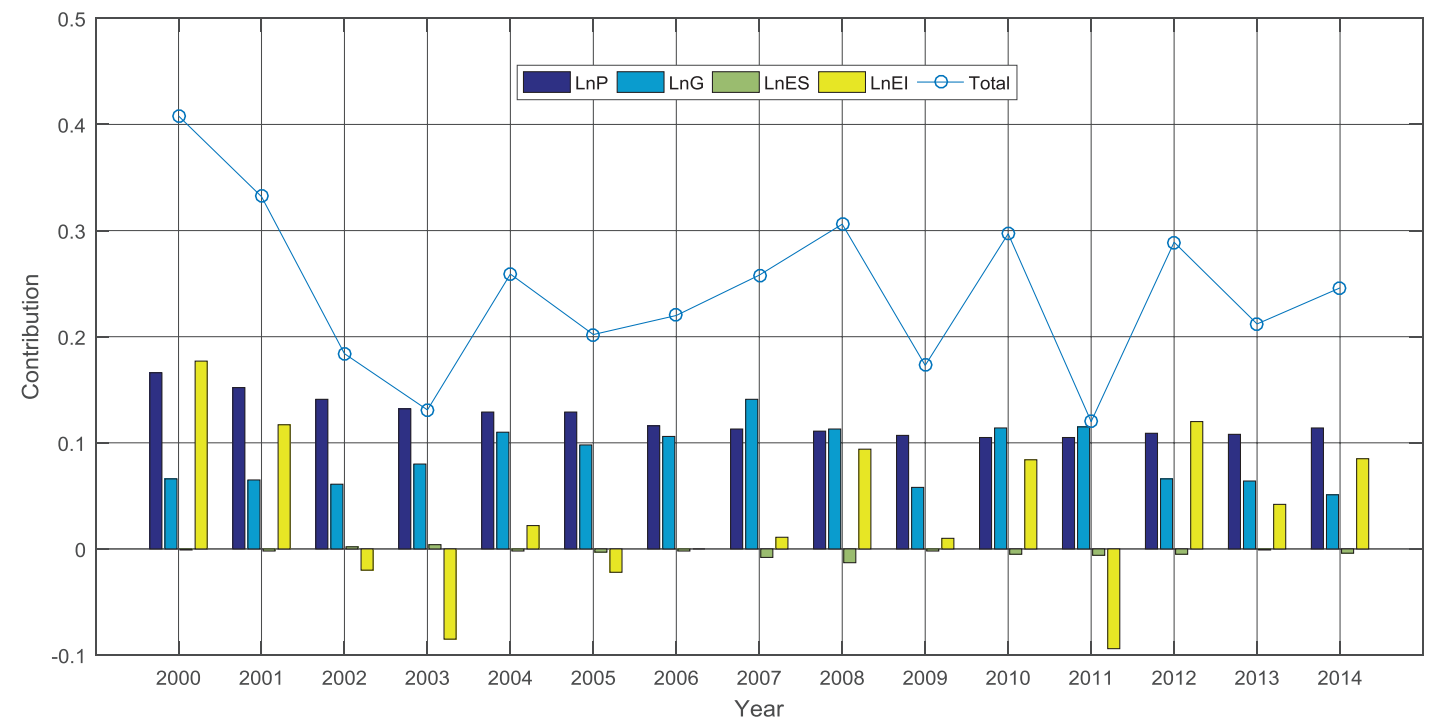

Fig. 6. Annual contribution of each variable to changes in China's electrification potential.

The governmental policies have great volatility in its contribution to the electrification potential during 19992014; this shows that the government has not formed a stable policy system for electrification. The contribution of government's policy support to the electrification potential is $15 \%$. The above analysis shows that the potential of electrification is more sensitive to government's policy support, so the government should introduce relevant policies to promote the development of electrification in China. Adjusting the energy structure and increasing the proportion of clean energy consumption will require the government to introduce corresponding policies. The government's policy is not only a strategic planning policy but also a series of related supporting policies, such as price policy, lowering electricity prices or increasing subsidies to increase the economics of electrification; fiscal and taxation policies, increasing subsidies for electrical equipment or collecting environmental pollution charges; Investment and financing policies, encouraging a variety of financing methods to solve the problem of financing difficulties in the electrification process. Through this series of policies to increase the proportion of clean energy in the final energy consumption, thereby improving the energy structure.

The contribution of GDP per capita to electrification potential shows a trend of increasing at first and then slowing down, mainly due to the changes in China's economic development. From 1999 to 2014, the contribution value of per capita GDP to the electrification potential is 1.307 , with a contribution rate of $36 \%$. From the above analysis we can see that the economic development will increase the potential of electrification. Therefore, we should continue to adhere to economic construction, reduce taxes and fees for enterprises and individuals, increase the income level of the people, and increase the purchasing power of electricity.
Over the past ten years, the contribution of technology to the potential of electrification is relatively small, and the contribution is decreasing year by year. This indicates that the impact of technology on the electrification potential is constantly weakening. However, from the above analysis, we can see that the level of technology will slow the trend of slowing growth in electrification potential when China's economic growth slows down. Therefore, in order to reduce the electric intensity, it is necessary to improve the technical level of electrification. The first is to increase investment in research and development of related technologies, and strengthen cooperation between enterprises and universities or scientific research institutions, speeding up the transformation of electrification technology from research to application, increasing marketing efforts for electric vehicle, electric kiln furnaces, commercial induction cookers and other electrification technologies. The electric intensity is reduced by advancement and use of related technologies.

\section{Acknowledgements}

This paper is supported by the National Natural Science Foundation of China (Grant No.71964022).

\section{Conflict of Interest}

The authors declare no conflict of interest.

\section{References}

1. SUN W., XU Y. Using a back propagation neural network based on improved particle swarm optimization to 
study the influential factors of carbon dioxide emissions in Hebei Province. Journal of Cleaner Production, 112, 1282, 2016

2. AYRES R.U., JEROEN C.J.M., VAN DEN.BERGH., LINDENBERGER D., WARR B. The underestimated contribution of energy to economic growth. Structural Change \& Economic Dynamics, 27, 79, 2013.

3. WEI S., LIU M. Wind speed forecasting using FEEMD echo state networks with RELM in Hebei, China. Energy Conversion \& Management, 114, 197, 2016.

4. CHEN S. Energy consumption, $\mathrm{CO} 2$ emission and sustainable development in Chinese industry. Economic Research Journal, 2 (2009), 113, 2009.

5. Duchin FBSteenge., A VERCELLI Structural Change and Economic Dynamics. Environment and economics, 2(2), 251, 1991.

6. DINCER I. Renewable energy and sustainable development: a crucial review. Renewable \& Sustainable Energy Reviews, 4 (2), 157, 2002.

7. WANG W., HUANG K. The Strategy of Electric Power Alteration:Opportunities, Challenges and Policy Options. Journal of North China Electric Power University, 2014.

8. WANG Z.L., GAO J.H., JIANG W. Electric power alternatives potentional in Shandong and policy analysis. Power Demand Side Management, 2014.

9. YAN T., CHENG H., ZENG P., MA Z., ZHANG L., TIAN S. System Architecture and Key Technologies of Energy Internet. Power System Technology, 2016.

10. WEI B.L. China's Energy Development Thirteenth FiveYear Plan Review and Thirteenth Five-Year Plan Outlook. Beijing: Economy\& Management Publishing House, 288, 2016.

11. National Development and Reform Commission. Outline of the Thirteenth Five-Year Plan for National Economic and SocialDevelopmentofthe People's Republic of China.XinhuaNewsAgency:http://www.gov.cn/ xinwen/201603/17/content 5054992.htm, (accessed on 17/03/2016).

12. XIA H.J., LIN H.Y., ZHANG W., YANG S., GUO W., MIAO B. Research on development potential of regional electric energy substitution based on multi model. Science \& Technology Management Research, 2018.

13. TANG J.M., LIU J.Y., YANG K., LIU Y.B. Short-Term Load Combination Forecasting by Grey Model and Least Square Support Vector Machine. Power System Technology, 33 (3), 63, 2009.

14. TAN Z., ZHANG J., WU L., DING Y., SONG Y. A Model Integrating Econometric Approach With System Dynamics for Long-Term Load Forecasting. Power System Technology, 35 (1), 186, 2011.

15. CAO D.L., YUAN Y., LI Z.X. Application and Efficiency Evaluation of Alternative Energy. Power System \& Clean Energy, 2011.

16. WANG D.S., LIU M.R., BAI X.F., DING H. The situation analysis of civil coal in the Beijing-Tianjin-Hebei region. Coal Quality Technology, 2016.

17. DENNIS K. Environmentally Beneficial Electrification: Electricity as the End-Use Option. Electricity Journal, 28 (9), 100, 2015.

18. DENNIS K., COLBURN K., LAZAR J. Environmentally beneficial electrification: The dawn of 'emissions efficiency'. Electricity Journal, 29 (6), 52, 2016.

19. NEEDELL Z.A., MCNERNEY J., CHANG M.T., TRANCIK J.E. Potential for widespread electrification of personal vehicle travel in the United States. NATURE ENERGY, 1 (9), 16112, 2016.
20. MOREDA G.P., MUÑOZ-GARCÍA M.A., BARREIRO P. High voltage electrification of tractor and agriculturalmachinery - A review. Energy Conversion \& Management, 115, 117, 2016.

21. ZHONG W.U., QIANG L.I., XU H.T. Efficiency evaluation of alternative energy in heat supply system. Journal of Zhejiang University of Technology, 2016.

22. CHONG Q., CHENG L., ZHONG M., FENG W., WANG S., YANG D. Fuzzy comprehensive evaluation of environmental benefits of electric energy substitute technology based on improved ANP. Electrical Measurement \& Instrumentation, 2017.

23. JAVADI F.S., RISMANCHI B., SARRAF M., AFSHAR O., SAIDUR R., PING H.W., RAHIM N.H. Global policy of rural electrification. Renewable \& Sustainable Energy Reviews, 19 (1), 402, 2013.

24. STEINBERG D. Electrification \& Decarbonization: Exploring U.S. Energy Use and Greenhouse Gas Emissions in Scenarios with Widespread Electrification and Power Sector Decarbonization. National Renewable Energy Laboratory, 1, 111, 2017.

25. XU Z., NTHONTHO M., CHOWDHURY S. Rural electrification implementation strategies through microgrid approach in South African context. International Journal of Electrical Power \& Energy Systems, 82, 452, 2016.

26. MOLYNEAUX L., WAGNER L., FOSTER J. Rural electrification in India: Galilee Basin coal versus decentralised renewable energy micro grids. Renewable Energy, 89, 442, 2016.

27. TROTTER P.A. Rural electrification, electrification inequality and democratic institutions in sub-Saharan Africa. Energy for Sustainable Development, 34, 111, 2016.

28. PODE R., PODE G., DIOUF B. Solution to sustainable rural electrification in Myanmar. Renewable \& Sustainable Energy Reviews, 59, 107, 2016.

29. LI Y., CHEN Z.S. Evaluation Index System and Evaluation Method of China's Regional Potential for Electrical Energy Substitution. Mathematical Problems in Engineering, 2016.

30. WANG Z.L., GUO J.H., JIAO W. Electric power alternatives potentional in shandong and policy analysis. Power Demand Side Management, 2014.

31. SUN Y., ZHOU S., SHAN B., JIAO D., CAO F. Analysis of electric power alternative potential under multi-scenario. Power System Technology, 41 (1), 118, 2017.

32. YI S., MO S., SHAN B., CAO F. Electric Energy Substitution Potential Analysis Method Based on Particle Swarm Optimization Support Vector Machine. Power System Technology, 2017.

33. R E.P., HOLDREN J.P. Impact of Population Growth. Science, 171, 1212, 1971.

34. EHRLICH P.R., HOLDREN J.P. A Bulletin Dialogue on "The Closing Circle," Critique. Bulletin of the Atomic Scientists, 28 (5), 1972.

35. YU X., GENG Y., DONG H., ULGIATI S., LIU Z., LIU Z., MA Z., TIAN X., SUN L. Sustainability assessment of one industrial region: $A$ combined method of emergy analysis and IPAT (Human Impact Population Affluence Technology). Energy, 107, 818, 2016.

36. MA M., YAN R., DU Y., MA X., CAI W., XU P. A methodology to assess China's building energy savings at the national level: An IPAT-LMDI model approach. Journal of Cleaner Production, 143, 2016. 
37. DU Q., CHEN Q., LU N. Forecast of China's carbon emissions based on modified IPAT model. Acta Scientiae Circumstantiae, 32 (9), 2294, 2012.

38. ZHU X., LIU Z. Study of Dalian water resources eff iciency on IPAT equation. Journal of Dalian University of Technology (Social Sciences), 27 (3), 39, 2006.

39. DIETZ T., ROSA E.A. Rethinking the environmental impacts of population, Affluence and technology. Human Ecology Review, 1, 227, 1994.

40. FAN Y., LIU L.C., WU G., WEI Y. Analyzing impact factors of $\mathrm{CO} 2$ emissions using the STIRPAT model. Environmental Impact Assessment Review, 26 (4), 337, 2006.

41. ZHANG W. Prediction and scenario analysis of industrial carbon emissions in Shaanxi Province based on STIRPAT model. Renewable Energy Resources, 2017.

42. QU S., GUO C. Forecast of China's carbon emissions based on STIRPAT model. China Population Resources \& Environment, 2010.

43. SUN W., MENG M., HE Y. $\mathrm{CO}_{2}$ Emissions from China's Power Industry: Scenarios and Policies for $13^{\text {th }}$ Five-Year Plan. Energies, 9 (10), 825, 2016.

44. POLENSKE K.R., LIN X. Conserving energy to reduce carbon dioxide emissions in China. Structural Change \& Economic Dynamics, 4 (2), 249, 1993.

45. YANG L.S., LIN B.Q. Carbon dioxide-emission in China's power industry: Evidence and policy implications. Renewable\& Sustainable Energy Reviews, 7 (60), 258, 2016.
46. WOLD S., ALBANO C., DUNN W.J., ESBENSEN K., HELlBERG S., JOHANSSON E., SJÖSTRÖM M. Pattern Recognition: Finding and Using Regularities in Multivariate Data; Food Research and Data Analysis; Applied SciencePublishers: London, UK, 1983.

47. LI H., MU H., ZHANG M., GUI S. Analysis of regional difference on impact factors of China's energy - Related $\mathrm{CO}_{2}$, emissions. Energies, 39 (1), 319, 2012.

48. WANG Z.X. A genetic algorithm-based grey method for forecasting food demand after snow disasters: an empirical study. Natural Hazards, 68 (2), 675, 2013.

49. PAIT Y., HANAKI K., CHIOU R.J Forecasting Hourly Roadside Particulate Matter in Taipei County of Taiwan Based on First-Order and One-Variable Grey Model. Clean - Soil Air Water, 41 (8), 737, 2013.

50. DENG J.L. Control problems of grey systems. Systems \& Control Letters, 1 (5), 288, 1982.

51. MENG M., NIU D., SUN W. A small-sample hybrid model for forecasting energy-related $\mathrm{CO}_{2}$ emissions. Energy, 64 (1), 673, 2014.

52. XU M.J., HU Z.G.TAN X.D. Scenario analysis onmid-long term energy and electricity demand and carbon emission in China. electric power, 45 (4), 101, 2012.

53. XU H.C. After the $19^{\text {th }}$ National Congress of China, the economic trend predicts. The top 10 challenges and 10 changes in the Chinese economy in the next 10 years. https://zhidao.baidu.com/question/107448742.html, 201711-29/2018-04-18 (accessed on 18/04/2018). 